\title{
Comparative statics for real options on oil: What stylized facts?
}

\author{
Diderik Lund and Ragnar Nymoen \\ E-mail: diderik.lund@econ.uio.no; ragnar.nymoen@econ.uio.no \\ Department of Economics, University of Oslo \\ P.O.Box 1095, Blindern, NO-0317 Oslo, Norway
}

\begin{abstract}
An important application in the real options literature has been to investments in the oil sector. Two commonly applied "stylized facts" in such applications are tested here. One is that the correlation of the returns on oil and the stock market is positive, the other that it is invariant to changes in oil price volatility. Both are rejected in data for 1993-2008 for crude oil and the S\&P 500 stock market index. Based on real options theory, consequences are pointed out. A widespread idea, that higher volatility leads to increased value and postponed investment, is not necessarily valid.
\end{abstract}

KEYWORDS: real options, oil, volatility, CAPM, comparative statics JEL CLASSIFICATION NUMBERS: D92; G13; G31; Q30; Q40 


\section{Introduction}

The seminal model in McDonald and Siegel (1986) considers the "value of waiting to invest." A firm can make an irreversible investment $I>0$ to obtain a stochastic asset value $V_{t}$. This real option is analogous to a financial American call option. If the option to invest lasts forever, there is a closed form solution to the value. If also the investment cost is deterministic, the value is a function of five variables, among these the volatility of the underlying asset, $\sigma$, and a variable known as the rate-of-return shortfall, $\delta .{ }^{1}$

The partial derivatives of the function reveal that the option value is increasing in $\sigma$ and decreasing in $\delta$. Grullon et al. (2012, p. 1500) write that "One of the main implications of real options theory is that a real option's value is increasing in the volatility of an underlying process." This depends critically on whether $\delta$ will change when volatility changes.

A central and early application of real options theory has been to oil projects. ${ }^{2}$ The present study concentrates on oil. The relevance for other outputs is an empirical question, but the general lesson, not to rely on "stylized facts" that are not verified, carries over.

Section 2 reviews the previous literature most closely related to this study. Section 3 briefly presents the model and our motivation. Section 4 presents an empirical specification which corresponds to the prevailing practice of comparative statics. This is tested on data for 1993-2008 for crude oil and the U.S. stock market. Section 5 contains the empirical results, rejecting two "stylized facts" commonly relied upon. Section 6 concludes.

\footnotetext{
${ }^{1}$ In McDonald and Siegel (1984), $\delta$ is called the rate-of-return shortfall. In much of the real options literature, e.g., Brennan and Schwartz (1985), $\delta$ is known as the convenience yield, since such a yield would explain why storage of the asset may occur in spite of the shortfall.

${ }^{2}$ See, e.g., Tourinho (1979), Ball and Bowers (1983), Paddock et al. (1988), Bjerksund and Ekern (1990), and Dixit and Pindyck (1994).
} 


\section{Previous literature}

Two previous articles in this journal discuss the possible connection between changes in $\sigma$ and $\delta$, and the consequences for real option values. Both take the model of McDonald and Siegel (1986) as their starting point.

Davis (2002) sets out to examine critically the prevailing idea that real option values are increasing in volatility. He motivates the discussion by its relevance for growth options, possibly misvalued during the dotcom bubble in the years before 2002. Based on a theoretical discussion he shows that the sign of $d V / d \sigma$ is ambiguous. Examples show that the value of at-the-money or in-the-money growth options is likely to be decreasing in volatility.

Kanniainen (2009) also criticizes the prevailing view. He shows how the consequences of the assumed relation between $\sigma$ and $\delta$ depends on a basic assumption in the model: While McDonald and Siegel (1986) assume that exercising the option gives a project value $V_{t}$ which follows a geometric Brownian motion (GBM), Davis (2002) assumes that exercising the option starts a perpetual cash flow stream, which follows a GBM. The latter assumption introduces another channel through which a change in $\delta$ will affect option value, namely the discount rate for the expected cash flow stream. Kanniainen (2009) considers both cases, combined with different assumptions on the relation between $\sigma$ and $\delta .^{3}$ For some cases there are unambiguous results, for others, ambiguous.

While the two articles clearly demonstrate the importance of some underlying assumptions in these models, they do not test the assumptions empirically. The present study is an attempt to perform such tests, closely related to the same literature. But the empirical focus here is on oil, which is not the case for these two previous articles.

The most direct approach to testing relations between $\sigma, \delta$, and option values would rely on $\delta$ being observable in a futures market. A central reference is Litzenberger and Rabinowitz (1995), who use data for oil 1984-1992. An equilibrium model of the oil market with atomistic, heterogeneous suppliers exercising real options, and with uncertainty

\footnotetext{
${ }^{3}$ As explained below, two assumptions on a correlation or covariance being constant are combined with assumptions on the correlation (and covariance) being positive or negative.
} 
originating on the demand side, leads to three testable hypotheses. None are rejected by the data. We comment on this at the end of section 5 .

\section{The model}

The model is taken directly from McDonald and Siegel (1986) and Dixit and Pindyck (1994). A firm has the option to make an irreversible investment $I>0$ to create an asset with value $V_{t}$. The option lasts indefinitely, but can only be exercised once. For simplicity $I$ is assumed to be fixed, ${ }^{4}$ while $V_{t}$ is a Geometric Brownian Motion (GBM) with drift,

$$
d V_{t}=\alpha V_{t} d t+\sigma V_{t} d Z_{t}
$$

where $t$ is time, $\alpha$ is the expected growth rate, $\sigma$ is a constant volatility, and $d Z_{t}$ is the increment of a standard Wiener process.

The firm maximizes its market value. The optimal time for the firm to invest is the first time $V_{t}$ reaches a trigger level $V^{*}$ from below. Defining the constant $\gamma$ as

$$
\gamma=\frac{1}{2}-\frac{r-\delta}{\sigma^{2}}+\sqrt{\left(\frac{1}{2}-\frac{r-\delta}{\sigma^{2}}\right)^{2}+\frac{2 r}{\sigma^{2}}},
$$

the optimal $V^{*}$ is

$$
V^{*}=\frac{\gamma}{\gamma-1} I
$$

cf. equations (14) and (24) in Dixit and Pindyck (1994, pp. 142, 152). They show that when $V_{t}$ is below the trigger, the value of the perpetual option is

$$
F\left(V_{t}, I, r, \sigma, \delta\right)=A V_{t}^{\gamma}
$$

with the constant $A$ defined by

$$
A=\frac{V^{*}-I}{\left(V^{*}\right)^{\gamma}}=I^{1-\gamma}(\gamma-1)^{\gamma-1} \gamma^{-\gamma} .
$$

The model describes a perpetual American call option on an asset with a rate-ofreturn shortfall, $\delta$. For a financial option, the underlying asset could be a stock with a continuous dividend yield rate $\delta$, in case the option is not payout protected.

\footnotetext{
${ }^{4}$ McDonald and Siegel (1986) also consider the case where both $V$ and $I$ are GBMs.
} 
For a real option, Dixit and Pindyck (1994) consider alternative specifications of the underlying asset, with increasing complexity. In the simplest case, the underlying asset is one unit of output with price $P_{t}$, so that $V_{t} \equiv P_{t}$. This is sufficient for our purpose, and is the only case to be discussed here. ${ }^{5}$

Davis (2002, p. 220) points out that "the derivative $\partial F / \partial \sigma$ is complex and difficult to sign". ${ }^{6}$ Both he and Dixit and Pindyck (1994) thus resort to numerical examples in order to illustrate the partial effects. The examples show that $\partial F / \partial \sigma>0$ and that $\partial F / \partial \delta<0$ (Dixit and Pindyck, 1994, pp. 154, 156). Furthermore, they (see also Davis (2002, p. 223)) show that $\partial V^{*} / \partial \sigma>0$ and that $\partial V^{*} / \partial \delta<0$ (Dixit and Pindyck, 1994, pp. 153, 157).

In addition to the direct, positive effect of volatility on option value, there can be a reinforcing or counteracting effect if a change in $\sigma$ coincides with a change in $\delta{ }^{7}$ Typically it is assumed that higher $\sigma$ leads to a higher $\delta$ and a counteracting effect, but we show that one should be aware of the opposite possibility.

The rate-of-return shortfall is defined as

$$
\delta=\mu-\alpha
$$

where $\mu$ is the required expected return that would induce investors to hold the asset even if they experience no convenience yield. A $\delta>0$ can be interpreted as follows. The asset's expected return does not satisfy investors' requirements for an investment asset, given that they will benefit only from the asset's price appreciation. For real options, this is the typical case, while for financial options, $\delta=0$ is seen as the base case. ${ }^{8}$ The

\footnotetext{
${ }^{5}$ In a subsequent chapter, Dixit and Pindyck (1994, pp. 177-186) interpret the asset as the present value of a perpetual revenue stream, the sales value of production, first considered with no operating cost. In that case, $V_{t} \equiv P_{t} / \delta$, i.e., there is an additional link between the arguments of the option value function. This opens for more ambiguity in comparative statics, see also Kanniainen (2009).

6 "Complex" is used in its everyday meaning, not in the mathematical meaning.

${ }^{7}$ There may also be simultaneous changes in other variables, for instance the interest rate. These possibilities are outside the scope of this study.

${ }^{8}$ An important achievement of Black and Scholes (1973) was the ability to find option values without any prediction of expected return of the underlying asset. But when that asset has a rate-of-return
} 
partial effect (for given $V_{t}, \sigma_{p}$, etc.) of increased $\delta$ is thus lower call option value, but also a lower trigger, since waiting to invest is less attractive. However, it may be misleading to consider each partial derivative of $F$ and $V^{*}$ in isolation. It is easy to imagine that $\delta$ depends on other variables, and $\sigma$ in particular. More risk can imply higher required return. This connection will be important if $\delta$ is not directly, independently observable.

The shortfall can be observable if a futures or forward market exists for the asset. But in many cases there is no such market, at least not for the long maturities that correspond to real investment projects. For oil, the markets are illiquid for maturities exceeding one year (Alquist and Kilian, 2010). When $\delta$ is not directly observable, many authors, including McDonald and Siegel (1986) and Dixit and Pindyck (1994), recommend to use the Capital Asset Pricing Model (CAPM), ${ }^{9}$

$$
\mu=r+\phi \sigma_{p} \rho_{p m}
$$

where $\phi=\left[E\left(r_{m}\right)-r\right] / \sigma_{m}$ is the market price of risk, $\rho_{p m}$ is the correlation of the return on $P_{t}, \ln \left(P_{t+1} / P_{t}\right)$, and that on the market portfolio, $r_{m}$. The $\sigma_{p}$, now with a subscript for clarity, was denoted $\sigma$ above.

The typical assumption is that $\alpha$ is invariant to changes in $\sigma_{p} \cdot{ }^{10}$ This will be maintained here. To determine from (6) whether $\delta$ is invariant to changes in $\sigma_{p}$, we ask whether $\mu$ is invariant. Thus, (7) is relevant. McDonald and Siegel (1986) acknowledge, in their footnote 14, that their results "ignore the possibility that changes in" [volatilities] "affect the required rates of return". Furthermore, "This assumption would be valid if the uncertainty is uncorrelated with the market portfolio or if investors are risk neutral." They state that the opposite case "can lead to ambiguity in the comparative static results."

shortfall, this achievement is undermined. Unless $\delta$ is directly observable, one may have to estimate it as a difference, as in (6).

${ }^{9}$ The CAPM (Sharpe, 1964; Lintner, 1965; Mossin, 1966) was extended by Merton (1973) to continuous time. The single-beta version of this extension is used in the real options literature. Among authors recommending to use the CAPM to find $\mu$ are Trigeorgis (1996), Salahor (1998), Laughton (1998), Sarkar (2000), Davis (2002), Lund (2005), Wong (2007), Gutiérrez (2007), Berg et al. (2009), Kanniainen (2009), Guthrie (2009), and Brooks and Chance (2014), some with reservations.

${ }^{10}$ Davis (2002, p. 216) has a brief discussion of this, with two references. 
On the other hand, Dixit and Pindyck (1994, p. 178) state that "when the $\sigma$ of the $P$ asset increases, $\mu$ must increase." From (7), this seems to rely on an assumption that $\rho_{p m}$ is positive and invariant to changes in $\sigma_{p}{ }^{11}$ Both of these assumptions are tested and rejected below.

Equation (7) can be rewritten as $\mu=r+\phi \sigma_{p m} / \sigma_{m}$, where $\sigma_{p m}$ is the covariance. The assumption of an unchanged $\mu$ is consistent with an unchanged covariance, as opposed to an unchanged correlation. For oil in particular, both of these alternative assumptions have appeared in the real options literature. Bradley (1998, p. 59) states that "we vary the level of price uncertainty, but keep the forward prices the same across models." This is consistent with a constant covariance if the CAPM is valid. Laughton (1998, eq. (A-1)) lets forward prices vary when $\sigma$ varies, consistent with a constant correlation.

The unchanged covariance follows, e.g., if the increase in volatility comes from some multiplicative noise, $X$, that is stochastically independent of $\left(r_{p}, r_{m}\right)$. When $E(X)=1$, and $\operatorname{var}(X)>0$, then the covariance is unaffected,

$$
\operatorname{cov}\left(r_{m}, X r_{p}\right)=E\left(r_{m} X r_{p}\right)-E\left(r_{m}\right) E\left(X r_{p}\right)=E(X) \operatorname{cov}\left(r_{m}, r_{p}\right)=\operatorname{cov}\left(r_{m}, r_{p}\right)
$$

In this case, the correlation is reduced as a result of the noise.

In the literature on real options, few authors discuss which assumption is the more reasonable, and they do not consider empirical tests. Davis (2002) has an extensive nonempirical discussion of the problem, with a general formulation indicating that both $\delta$, $\mu$, and $\alpha$ may be functions of $\sigma_{p}$. After introducing the CAPM, Davis (2002) treats the correlation as a constant. This is also found in Berg et al. (2009). Kanniainen (2009) considers both possibilities, although he stresses (p. 180) the prominence of the constant correlation assumption both in theoretical and empirical studies.

The two assumptions, correlation constant versus covariance constant, can be seen as opposite extremes. It may be more reasonable to invoke an intermediate assumption. Cappuccio and Moretto (2001, p. 11) state that "Which of these viewpoints is more plausible is, in general, an empirical matter ...."

\footnotetext{
${ }^{11}$ Clearly, the same two assumptions are made about $\phi$. Whether this is reasonable, is outside the scope of this study.
} 


\section{Empirical specification and data}

While the theoretical literature on real options discusses comparative statics results, there is less discussion of the interpretation and relevance of these results. The effect of a higher or lower volatility on the endogenous variables of a real options model will have practical relevance in various circumstances. One is that volatility could change over time for real options on a specific type of assets, such as oil fields. Another could be a comparison between different assets with different volatilities, but this is hardly the typical application, and will not be discussed further.

If a volatility changes over time, this is at odds with the theory as specified here. Valuation and optimal strategy have been derived under the assumption of a constant volatility. If there is the possibility of a changing volatility, this should have been present in the model to begin with. The stochastic process for the price of the underlying asset should have been specified differently, and the value and strategy would have been influenced by this. ${ }^{12}$

In the most common interpretation, changes in volatility over time, the comparative statics results are thus not useful from a purist point of view. A more pragmatic view is chosen because models with constant volatility are easy to solve. The analytical solutions have attracted substantial interest, both from theorists and practitioners, and this is also likely to be the case in the foreseeable future. Thus it is interesting to improve the practical relevance of the comparative statics results of such models, the purpose of the present study.

For an empirical investigation, it is necessary to decide what kind of deviation from a constant volatility one will estimate. There is no assumption here that volatility changes continuously over time, nor that there are probabilities for switching between various regimes. Instead the volatility changes will be taken from an existing study of structural breaks in volatility. A structural break is an operational concept that seems close to

\footnotetext{
${ }^{12}$ Ting et al. (2013) characterize real options with stochastic volatility. Deterministic volatility is less realistic, but the models are so much simpler that they are likely to be used in most applications for many years to come. This motivates the present study.
} 
the theoretical notion of an unanticipated change, with no specified probability for any particular magnitude or direction of that change. Under such a process with breaks, it may be imagined that the market's valuation and the decision maker's strategy may as well rely on models with constant volatility. The deviation from a purist view is as little as possible.

The breaks are found in the study by Ewing and Malik (2010) of crude oil spot prices 1993-2008. Based on their method, the data lead to an identification of three breaks in the volatility, i.e., in the standard deviation of relative changes ("returns") in the oil price. Apart from dummy variables that allow for these breaks, the oil price returns are assumed to follow a GARCH process, which is different from the GBM used in most option pricing models. ${ }^{13}$ The pragmatic defense of this procedure is that the breaks are taken to exist irrespective of the detailed assumptions made about the stochastic process. Unfortunately, this is not quite true: A subsequent study by Vivian and Wohar (2012) finds fewer breaks in volatility when they allow other parameters of the GARCH model to have breaks as well. Nevertheless, the break points found by Ewing and Malik (2010) will be used here. After all, if many parameters change, this does not correspond well with the theoretical notion of comparative statics, changing $\sigma_{p}$ while holding everything else constant.

The four periods $(i=1, \ldots, 4)$ delimited by the three breaks are shown in the first three columns of Table 1, including the volatility estimates from Table 3 of Ewing and Malik (2010). Fifteen years of daily data are used, and the standard deviation is based on one day as time unit. These are working days, about 250 per year.

The next section is based on oil spot prices and the Standard and Poor's 500 index for the stock market. The question is: Is $\rho_{p m}$ in period $i$ significantly different from $\rho_{p m}$ in period $i-1$ (for $i=2,3,4)$ ? If the answer is yes, one will have to reject the hypothesis that $\rho_{p m}$ is invariant to changes in volatility. The information here concerns the method in which the CAPM is used for estimating $\mu$ separately. The answers may be different for different breaks.

\footnotetext{
${ }^{13}$ There also exist GARCH real option models, starting with Duan (1995).
} 
Table 1: Estimates of parameters of the CAPM real options model

\begin{tabular}{cccccc}
\hline Regime & Dates & $\hat{\sigma}_{p}$ & $\hat{\rho}_{p m}$ & $\hat{\rho}_{p m} \hat{\sigma}_{p}$ & $\hat{\rho}_{p m} \hat{\sigma}_{m} \hat{\sigma}_{p}$ \\
\hline 1 & $1993.07 .01-1994.08 .29$ & 0.0191 & -0.1788 & $-3.41 \times 10^{-3}$ & $-1.86 \times 10^{-5}$ \\
2 & $1994.08 .30-1996.01 .08$ & 0.0142 & -0.0305 & $-4.33 \times 10^{-4}$ & $-2.33 \times 10^{-6}$ \\
3 & $1996.01 .09-2005.06 .13$ & 0.0259 & -0.0218 & $-5.65 \times 10^{-4}$ & $-6.68 \times 10^{-6}$ \\
4 & $2005.06 .14-2008.06 .30$ & 0.0191 & -0.0177 & $-3.39 \times 10^{-4}$ & $-3.08 \times 10^{-6}$ \\
\hline
\end{tabular}

Source: Own estimates, except $\hat{\sigma}_{p}$ taken from Ewing and Malik (2010).

Spot prices for crude oil are daily data for West Texas Intermediate (WTI), obtained from U.S. Energy Information Administration (2012). This is identical to the data in Ewing and Malik (2010), and the same time period was chosen, July 1993-June 2008. Data for the return on a market portfolio was taken from the total return index of Standard and Poor's 500 from the New York Stock Exchange. These data were obtained from the company S\&P Dow Jones Indices.

\section{$5 \quad$ Empirical results}

Within each of the four periods defined by the breaks, three variables of interest for the application of the CAPM have been estimated. The results are given in the last three columns of Table 1.

The first notable feature of the estimates is the fact that correlations and covariances are consistently negative throughout the fifteen years. This is also found in previous empirical studies. Deaves and Krinsky (1992, table 3) find negative, but insignificant correlations with the U.S. stock market in data for crude oil futures 1983-1990. Schwartz (1997) finds negative or insignificant values (for the risk premium, $\lambda$ in his notation) for oil in his one-factor model. Cifarelli and Paladino (2009, p. 364) summarize that "A number of studies, based on different data and estimation procedures, find a negative financial 
linkage between oil and stock prices i.e. a large negative covariance risk between oil and a widely diversified portfolio of assets." Another broad overview is given by Degiannakis et al. (2014), confirming the same pattern. Of course, the sign of the correlation may differ between different underlying assets and between different stock markets. ${ }^{14}$

Our purpose is not to explain the negative correlation. Research on this is found in Miller and Ratti (2009), Kilian and Park (2009), and Filis et al. (2011). A basic intuition is to distinguish between supply side uncertainty and demand side uncertainty in the world oil market. If all uncertainty had been on the supply side, movements would be along a fixed demand curve. High oil prices would coincide with low oil quantity, and, likely, low returns in equity markets. If all uncertainty had been on the demand side, movements would be along a fixed supply curve. High oil prices would be caused by high demand, likely coinciding with high returns in equity markets. The empirical confirmation of a largely non-positive correlation since 1983 can be taken to indicate that supply uncertainty has dominated.

A negative correlation means that the required expected return according to the CAPM has been less than the risk free interest rate. To get an impression of the magnitudes, consider the product of the point estimates, $\hat{\rho}_{p m} \hat{\sigma}_{p}$. This should be multiplied by $\sqrt{250}$ to compare with yearly interest rates, under the assumption of a GBM. With the value of $\phi=0.4$, suggested by Dixit and Pindyck (1994, p. 148), the reduction in annualized $\mu$ below the risk free interest rate, cf. (7), would be 0.0217 in the first subperiod, i.e., 217 basis points. It would practically vanish in the second, third and fourth subperiods, fluctuating between 22 and 36 basis points. ${ }^{15}$

\footnotetext{
${ }^{14}$ For a natural resource, the correlation may be different between an importing country's stock market and that of an exporting country, where resource exporting firms will be more prominent. For another asset in a resource exporting country, Slade and Thille (1997, p. 634) find that "the rate of copper price appreciation is virtually uncorrelated with the return on the Toronto Stock Exchange".

${ }^{15}$ For the solutions of the real options model to be valid, $\delta>0$ is a necessary requirement. Whether this was the case during 1993-2008 is beyond the scope of this study, since we do not provide any ex ante estimate of $\alpha$. More generally, Roberts (2000) suggests that negative or low correlation is consistent with the flat or downward trend in natural resource prices. $\delta$ can be positive because the ex ante expected price growth, $\alpha$, may have been small.
} 
Table 2: Test of invariance of correlation. Daily data

\begin{tabular}{ccccc}
\hline Regime & Dates & $\hat{\sigma}_{p}$ & $\hat{\rho}_{p m}$ & $\mathrm{OP}[p$ value $]$ \\
\hline 1 & $1993.07 .01-1994.08 .29$ & 0.0191 & -0.1788 & \\
2 & $1994.08 .30-1996.01 .08$ & 0.0142 & -0.0305 & $-21.907[0.0000]$ \\
3 & $1996.01 .09-2005.06 .13$ & 0.0259 & -0.0218 & $-2.7410[0.0062]$ \\
4 & $2005.06 .14-2008.06 .30$ & 0.0191 & -0.0177 & $-2.0756[0.0380]$ \\
\hline
\end{tabular}

The estimated correlations and covariances, as well as $\rho_{p m} \sigma_{p}$, do not appear to be invariant to changes in volatility. In particular, there is a sharp increase in both correlation and covariance at the first break point. At the second and third break point, the covariance changes much more in relative terms than the correlation. For the period after the first break point, i.e., during September 1994 - June 2008, one could draw the preliminary conclusion that the correlation is close to zero and does not change much, in particular not at the third break point in June 2005. However, a statistical analysis is necessary to determine whether invariance can be rejected or not.

Another interesting observation from Table 1 is that the direction of changes in $\left|\rho_{p m}\right|$ is not always opposite of the direction of changes in $\sigma_{p}$. This contradicts the simple intuition from the example in equation (8).

The first hypothesis we want to test is invariance of the correlation coefficient with respect to the structural break in market volatility between regime 1 and 2, against the alternative of a structural break also in the correlation coefficient, formally $H_{0}: \rho_{1 p m}=$ $\rho_{2 p m}$, against $H_{1}: \rho_{1 p m} \neq \rho_{2 p m}$.

Since there are three breaks in volatility, we also want to test $H_{0}: \rho_{2 p m}=\rho_{3 p m}$ against $H_{1}: \rho_{2 p m} \neq \rho_{3 p m}$, and $H_{0}: \rho_{3 p m}=\rho_{4 p m}$ against $H_{1}: \rho_{3 p m} \neq \rho_{4 p m}$.

We use the test suggested by Omelka and Pauly (2012). This is a studentized asymptotic test that does not require that $\Delta \ln \left(S P_{t}\right)$ and $\Delta \ln \left(O I L_{t}\right)$ are jointly normal.

We refer to this statistic as the OP-test. In Table 2 it is reported in the right column with the asymptotic $p$ values. At a 5 percent significant level, the null hypothesis of invariance is rejected for all three break points.

To check the robustness of the results, we have also used weekly data. These were 
Table 3: Comparing annualized estimates from weekly and daily data

\begin{tabular}{ccccccr}
\hline & & \multicolumn{2}{c}{ Daily data } & & \multicolumn{2}{c}{ Weekly data } \\
\cline { 3 - 4 } \cline { 6 - 7 } Regime & Years & $\sqrt{250} \hat{\rho}_{p m} \hat{\sigma}_{p}$ & $0.4 \sqrt{250} \hat{\rho}_{p m} \hat{\sigma}_{p}$ & & $\sqrt{52} \hat{\rho}_{p m} \hat{\sigma}_{p}$ & $0.4 \sqrt{52} \hat{\rho}_{p m} \hat{\sigma}_{p}$ \\
\hline 1 & $1993-94$ & -0.0540 & -0.0215 & 0.0290 & 0.0116 \\
2 & $1994-96$ & -0.0068 & -0.0027 & -0.0057 & -0.0023 \\
3 & $1996-05$ & -0.0089 & -0.0036 & -0.0099 & -0.0040 \\
4 & $2005-08$ & -0.0054 & -0.0021 & -0.0225 & -0.0090 \\
\hline
\end{tabular}

constructed from daily data by two alternative methods, averaging the level data for each calendar week, or using only Wednesday data. Both methods produced similar results.

The main results are that correlations are again negative and vary across the subperiods, but with one exception: In weekly data the correlation with the stock market returns is positive for the first period. This is $\hat{\rho}_{p m}=0.0610$ based on averages, and $\hat{\rho}_{p m}=0.0986$ based on Wednesday data, as opposed to $\hat{\rho}_{p m}=-0.1788$ from daily data. This raises doubts about the assumption of the returns being correlated GBM's. If they had been, the weekly returns for Wednesday data would also be correlated GBM's with the same correlations.

For subperiods $2-4$, however, the results are similar. The point estimates from Wednesday data are summarized in Table 3, with annualized estimates to allow comparisons.

Again, the value $\phi=0.4$ is used, and the columns that include this factor show the CAPM risk premium in the annual required expected returns, annualized $\phi \rho_{p m} \sigma_{p}$. For the latter three subperiods these are small in absolute values, also when computed from weekly data. For the second and third period, the annualized estimates for the two alternative frequencies are quite similar. For the last period, 2005-08, there is again a divergence between estimates based on daily and weekly data. But in this case, both are significantly negative.

Even though positive correlations were rejected in daily data for all four subperiods, we have done a further test of robustness of this result by considering correlations for 
rolling windows of shorter lengths, 80 working days. ${ }^{16}$ Among the 3677 windows, 57.8 percent have negative point estimates for $\rho_{p m}$, while the remaining 42.2 percent have positive point estimates. For most windows (89 percent of them, to be precise), 95 percent confidence intervals for $\hat{\rho}_{p m}$ include both positive and negative values. But 9.4 percent of the windows have only negative values in the confidence interval, while 1.6 percent of the windows have only positive values. This suggests that nonpositivity of correlations in daily data is a fairly robust result for these 15 years. An interpretation is that if there were periods with high demand fluctuations, these periods typically also had high supply fluctuations, so that the overall correlation was almost never significantly positive.

Finally, to get an idea of the magnitudes of the estimated changes, consider the numerical effects on call option values and triggers. While a comparative-statics analysis typically looks at changes in one variable at a time, there will now be changes in two variables simultaneously, $\sigma_{p}$ and $\rho_{p m}$. For these two, use the point estimates from daily data during each of the four subperiods defined in Table 1, but keep the other variables, $V_{t}, I, r, \alpha$, and $\phi$, fixed. Equations (6) and (7) will be applied to compute the change in $\delta$ that follows from a simultaneous change in $\sigma_{p}$ and $\rho_{p m}$.

The call option value is defined by (4). The trigger value for $V, V^{*}$, is defined by (3) and (2). Numbers similar to those in Dixit and Pindyck (1994, p. 153f) will be used as an example. With annual rates, the numbers are $r=0.04, \phi=0.4$, and $I=1$ is the required investment. The call option considered here has $V_{t}=I$, i.e., it is "at the money." Moreover, $\alpha$ is chosen to be 0.01 , so that $\delta$ is always positive, although very small when systematic risk is negative. The last term in (7), the product of the three factors $\phi \sigma_{p} \rho_{p m}$, will have the negative numerical annualized values found in the fourth column of Table 3. This leads to a value of $\delta$ from (6). The annualized volatility numbers are $\sqrt{250}$ times the estimates in Table 2. The resulting values are given in Table 4 .

For all three breaks, the triggers and the call option values do indeed move in the same directions as the changes in volatility. This is related to the corresponding changes

\footnotetext{
${ }^{16}$ With data for 3757 working days, there are $3757-80=3677$ such partly-overlapping windows. Some windows include data from two adjacent subperiods among the four original subperiods.
} 
Table 4: Example of at-the-money call option values and triggers

\begin{tabular}{rrrrrr}
\hline Regime & $\sigma_{p}$ & $\rho_{p m}$ & $\delta$ & $V^{*}$ & $F\left(V_{t}\right)$ \\
\hline 1 & 0.302 & -0.1788 & 0.0084 & 10.74 & 0.711 \\
2 & 0.225 & -0.0305 & 0.0273 & 2.88 & 0.372 \\
3 & 0.410 & -0.0218 & 0.0264 & 5.41 & 0.556 \\
4 & 0.302 & -0.0177 & 0.0279 & 3.68 & 0.448
\end{tabular}

All data are converted to annual rates. Source: Own calculations.

in $\delta$. For all three breaks, $\delta$ moves in the opposite direction of $\sigma_{p}$. There is thus no counteracting effect to the positive effect of volatility on option value. This would be an unambiguous reuslt if $\rho_{p m}$ had been negative and constant (when we maintain that $\alpha, \phi$, and $r$ are constants).

However, $\rho_{p m}$ is not constant, and the simplicity of the result is deceptive. ${ }^{17}$ Consider instead a jump from regime 1 to regime 3. Both $\sigma_{p}$ and $\delta$ are increased, due to a substantial reduction in $\left|\rho_{p m}\right|$. Considering the effects on $V^{*}$ and $F\left(V_{t}\right)$, the much higher $\delta$ counteracts the effect of a higher $\sigma$, so both $V^{*}$ and $F\left(V_{t}\right)$ are reduced. With a negative and possibly varying $\rho_{p m}$, a change in $\delta$ may or may not go in the same direction as a change in $\sigma_{p}$. A further exploration of possible constellations of results is not pursued here.

Considering the three breaks between adjacent regimes as they appear in the data, higher volatility coincides with lower systematic risk, thus a lower rate-of-return shortfall. One could say that this rescues the standard assumption, that higher volatility results in, or at least coincides with, higher triggers and option values. The results should nevertheless warn researchers to be more careful about assumptions underlying comparative statics. In particular, the robust negative correlations contradict what is often assumed in the real options literature.

The motivation for bringing in the CAPM is the lack of markets for derivatives with long enough maturities. However, our results could also be compared with the direct

\footnotetext{
${ }^{17}$ Thanks to a referee for pointing this out to us.
} 
approach in Litzenberger and Rabinowitz (1995), which is the more attractive approach for shorter maturities. They have no use for the concepts of systematic risk and required expected returns. Their theory does not allow for supply uncertainty. Based on the negative correlations found by us and others, we suggest that this may be a weakness. However, irrespective of this, we take note of their empirical results, which seem to contradict the changes of $\sigma$ and $\delta$ in opposite directions in table 4. They find (their Table V and Table VI) that higher volatility coincides with higher backwardation (for 19841992, for maturities less than a year). Since higher backwardation means higher $\delta$ (see, e.g., McDonald (2006, p. 181)), it contradicts what we find at each of the three breaks. We are not able to reconcile these results. We cannot draw conclusions from our results about the directly observed $\delta$, since we rely on additional maintained assumptions, the CAPM and some of its parameters. Our message concerns the applications of the CAPM to real options models, which should be more careful about relying on "stylized facts."

\section{Conclusion}

This paper has tested two important assumptions underlying a number of studies of real options, that the correlation of the returns on oil and the stock market is positive and invariant to changes in oil price volatility. The theoretical discussion has shown the role of the assumptions when the CAPM is used to estimate the rate-of-return shortfall.

During the 15-year period July 1993 - June 2008, the study by Ewing and Malik (2010) has found three breaks in volatility, i.e., four subperiods with different levels of the volatility of the change in the logarithm of the oil price. We interpret these breaks as the empirical counterparts of the "change in volatility" which is a topic of theoretical comparative statics results. Accordingly, the question about invariance has been, is the correlation invariant to such changes? This is clearly rejected in the tests.

Consistently with previous empirical studies, this study finds that the correlation has been negative in daily data for each of the four subperiods. This indicates that at the three breaks, there has not been a counteracting (negative) indirect effect of volatility on a real call option on oil. The estimates show that the absolute value of the correlation 
has fallen both between the first and second subperiod (and also between the third and fourth), when volatility has decreased, and between the second and third, when volatility has increased. As a robustness check, weekly data were also tested. Only for the first subperiod, 1993-94, the results were not confirmed. A positive correlation estimated suggests that the GBM assumption does not hold for that subperiod.

For valuation of real options, a negative correlation removes one source of ambiguity in comparative statics results. But the empirical results indicate that changes in volatility can lead to changes in the same or opposite direction in the correlation, so the ambiguity is still there. An assumption that the covariance is invariant to volatility changes is also not confirmed in the data. Theoretical discussions need to hold all possibilities open.

\section{Acknowledgements}

Thanks to two anonymous referees, Kjell Arne Brekke, Graham Davis, Kristin Linnerud, Robert McDonald, Bernt Arne Ødegaard, and conference participants at NAE (2013 Stavanger), OxMetrics (2013 Aarhus), European IAEE (2014 Rome), CenSES/ CICEP/CREE (2014 Trondheim), and the 19th annual Real Options conference (2015 Greece) for helpful comments to earlier drafts. Thanks to the Chair in Macroeconomics and Monetary Policy at the Dept. of Economics, Univ. of Oslo, for financial data support and to Sofie Kjernli-Wijnen for research assistance. All numerical results in this paper have been produced with OxMetrics 6.30 and PcGive 13.30, cf. Doornik (2009) and Doornik and Hendry (2009). 


\section{References}

Alquist, R. and Kilian, L. (2010) What do we learn from the price of crude oil futures? Journal of Applied Econometrics, 25, 539-573.

Ball, R. and Bowers, J. (1983) Distortions created by taxes which are options on value creation: The Australian Resources Rent Tax proposal. Australian Journal of Management, 8, 1-14.

Berg, T., Mölls, S.H. and Willershausen, T. (2009) (Real-)options, uncertainty and comparative statics: Are Black and Scholes mistaken? Working paper 645, Institute for Business Administration, University of Kiel, Germany.

Bjerksund, P. and Ekern, S. (1990) Managing investment opportunities under price uncertainty: From 'last chance' to 'wait and see' strategies. Financial Management, 19, $65-83$.

Black, F. and Scholes, M. (1973) The pricing of options and corporate liabilities. Journal of Political Economy, 81, 637-654.

Bradley, P.G. (1998) On the use of modern asset pricing for comparing alternative royalty systems for petroleum development projects. The Energy Journal, 19(1), 47-81.

Brennan, M.J. and Schwartz, E.S. (1985) Evaluating natural resource investments. Journal of Business, 58, 135-157.

Brooks, R. and Chance, D. (2014) Some subtle relationships and results in option pricing. Journal of Applied Finance, 24, 94-110.

Cappuccio, N. and Moretto, M. (2001) Comments on the investment-uncertainty relationship in a real option model. Discussion paper 23-2001, Department of Economics, University of Padova, Italy.

Cifarelli, G. and Paladino, G. (2009) Oil price dynamics and speculation; a multivariate financial approach. Energy Economics, 32, 363-372. 
Davis, G.A. (2002) The impact of volatility on firms holding growth options. The Engineering Economist, 47, 213-231.

Deaves, R. and Krinsky, I. (1992) Risk premiums and efficiency in the market for crude oil futures. The Energy Journal, 13(2), 93-117.

Degiannakis, S., Filis, G. and Kizys, R. (2014) The effects of oil price shocks on stock market volatility: Evidence from European data. The Energy Journal, 35(1), 35-56.

Dixit, A.K. and Pindyck, R.S. (1994) Investment under Uncertainty. Princeton University Press, Princeton.

Doornik, J.A. (2009) An Introduction to OxMetrics 6. Timberlake Consultants, London.

Doornik, J.A. and Hendry, D.F. (2009) Empirical Econometric Modelling PcGive 13. Volume 1. Timberlake Consultants, London.

Duan, J.C. (1995) The GARCH option pricing model. Mathematical Finance, 5, 13-32.

Ewing, B.T. and Malik, F. (2010) Estimating volatility persistence in oil prices under structural breaks. The Financial Review, 45, 1011-1023.

Filis, G., Degiannakis, S. and Floros, C. (2011) Dynamic correlation between stock market and oil prices: The case of oil-importing and oil-exporting countries. International Review of Financial Analysis, 20, 152-164.

Grullon, G., Lyandres, E. and Zhdanov, A. (2012) Real options, volatility, and stock returns. Journal of Finance, 67, 1499-1537.

Guthrie, G.A. (2009) Real Options in Theory and Practice. Oxford University Press, Oxford.

Gutiérrez, Ó. (2007) Devaluating projects and the investment-uncertainty relationship. Journal of Economic Dynamics and Control, 31, 3881-3888.

Kanniainen, J. (2009) On the effects of uncertainty on investment timing and option value. The Engineering Economist, 54, 175-196. 
Kilian, L. and Park, C. (2009) The impact of oil price shocks on the U.S. stock market. International Economic Review, 50, 1267-1287.

Laughton, D.G. (1998) The management of flexibility in the upstream petroleum industry. The Energy Journal, 19(1), 83-114.

Lintner, J. (1965) The valuation of risk assets and the selection of risky investments in stock portfolios and capital budgets. Review of Economics and Statistics, 47, 13-37.

Litzenberger, R.H. and Rabinowitz, N. (1995) Backwardation in oil futures markets: Theory and empirical evidence. Journal of Finance, 50, 1517-1545.

Lund, D. (2005) How to analyze the investment-uncertainty relationship in real option models? Review of Financial Economics, 14, 311-322.

McDonald, R.L. (2006) Derivatives Markets. 2nd ed. Addison Wesley, Boston.

McDonald, R.L. and Siegel, D. (1984) Option pricing when the underlying asset earns a below-equilibrium rate of return: A note. Journal of Finance, 34, 261-265.

McDonald, R.L. and Siegel, D. (1986) The value of waiting to invest. Quarterly Journal of Economics, 101, 707-727.

Merton, R.C. (1973) An intertemporal capital asset pricing model. Econometrica, 41, $867-888$.

Miller, J.I. and Ratti, R.A. (2009) Crude oil and stock markets: Stability, instability, and bubbles. Energy Economics, 31, 559-568.

Mossin, J. (1966) Equilibrium in a capital asset market. Econometrica, 34, 261-276.

Omelka, M. and Pauly, M. (2012) Testing equality of correlation coefficients in two populations via permutation methods. Journal of Statistical Planning and Inference, 142, 1396-1406. 
Paddock, J.L., Siegel, D.R. and Smith, J.L. (1988) Option valuation of claims on real assets: The case of offshore petroleum leases. Quarterly Journal of Economics, 103, 479-508.

Roberts, M.J. (2000) Can portfolio theory explain flat and downward trends in natural resource prices? Unpublished paper, presented at the Second World Congress of Environmental and Resource Economists, Monterey, June 2002.

Salahor, G. (1998) Implications of output price risk and operating leverage for the evaluation of petroleum development projects. The Energy Journal, 19(1), 13-46.

Sarkar, S. (2000) On the investment-uncertainty relationship in a real options model. Journal of Economic Dynamics and Control, 24, 219-225.

Schwartz, E.S. (1997) The stochastic behavior of commodity prices: Implications for valuation and hedging. Journal of Finance, 52, 923-973.

Sharpe, W.F. (1964) Capital asset prices: A theory of market equilibrium under conditions of risk. Journal of Finance, 19, 425-442.

Slade, M.E. and Thille, H. (1997) Hotelling confronts CAPM: A test of the theory of exhaustible resources. Canadian Journal of Economics, 30, 685-708.

Ting, S.H.M., Ewald, C.O. and Wang, W.K. (2013) On the investment-uncertainty relationship in a real option model with stochastic volatility. Mathematical Social Sciences, $66,22-32$.

Tourinho, O.A.F. (1979) The valuation of reserves of natural resources: An option pricing approach. Ph.D. thesis, University of California, Berkeley.

Trigeorgis, L. (1996) Real Options. Managerial Flexibility and Strategy in Resource Allocation. M.I.T. Press, Cambridge, MA.

U.S. Energy Information Administration (2012) Petroleum \& other liquids. Internet page, data downloaded October 5, http://www.eia.gov/petroleum/data.cfm. 
Vivian, A. and Wohar, M.E. (2012) Commodity volatility breaks. Journal of International Financial Markets, Institutions and Money, 22, 395-422.

Wong, K.P. (2007) The effect of uncertainty on investment timing in a real options model. Journal of Economic Dynamics and Control, 31, 2152-2167. 